\title{
CHEMOSPHERE
}

\section{Soil screening for identifying ecological risk stressors using a battery of in vitro cell bioassays}

\author{
Ruiyang Xiao, Zijian Wang *, Chunxia Wang, Guo Yu \\ State Key Laboratory of Environmental Aquatic Chemistry, Research Center for Eco-Environmental Sciences, Chinese Academy of Sciences, \\ Shuangqing Road 18, Haidian District, P.O. Box 2871, Beijing 100085, PR China
}

Received 18 July 2005; received in revised form 4 November 2005; accepted 10 November 2005

Available online 10 January 2006

\begin{abstract}
Soil screening could be a process of identifying and defining areas, contaminants, and condition at the sites that warrant further attention for developing ecological risk assessments. In present work, a total of 41 surface soil samples from Tianjin, China were sampled and the soil organic extracts were evaluated using a battery of in vitro cell bioassays. The battery included ethoxyresorfin O-deethylase (EROD) with H4IIE rat hepatoma cells bioassay for Aryl hydrocarbon (Ah) receptor (Ah-agonists) effects, the SOS/umu bioassay for genotoxic effects, and human estrogen receptor recombinant yeast bioassay for estrogenic effects. The results have showed that total estrogenic effects in these soil samples was measured to be between 0.1 and $14.2 \mathrm{ng}$ EEQ kg ${ }^{-1}$ soil (d.w.); Ah-agonists effects assayed by EROD bioassay varied from $2.8 \mathrm{ng}$ TEQ kg ${ }^{-1}$ soil (d.w.) to $42.6 \mathrm{ng}$ TEQ kg-1 soil (d.w.), and the amounts of soil weight required for the extracts to lead positive result (IR 2.0) in the SOS/umu bioassay were between 3.9 and $31.3 \mathrm{mg}$ (d.w.) per well. In addition, the geographic distributions of Ah-agonists effects and genotoxic effects in Tianjin area exhibited a strong positive correlation with each other. However, the distribution of estrogenic effects with high levels in northwest Tianjin was markedly different from that of Ah-agonists effects, where the high levels were distributed in the urban of Tianjin, as well as coastal towns. It has been concluded that the toxicity assessment of surface soil using a battery of in vitro cell bioassays could provided meaningful information regarding characterization procedure in ecological risk assessment.
\end{abstract}

(c) 2005 Elsevier Ltd. All rights reserved.

Keywords: Ecological risk assessment; Soil; In vitro cell bioassays; Biomarkers

\section{Introduction}

Problems aroused from contaminated soils are currently an important issue which affected deleteriously on terrestrial and aquatic communities by complex mixtures of both known and unknown contaminants (Moore et al., 2004; Snape et al., 2004). Until recently, most ecological risk assessments for soils are based exclusively on guideline values, derived from laboratory toxicity tests (Citterio et al., 2002; Fernandez et al., 2005). However, a major limitation of this approach is that most hazardous chemicals in soil are unknown. Thus, most toxicological data available are

\footnotetext{
${ }^{*}$ Corresponding author. Tel.: +86 10 62849140; fax: +86 1062923543. E-mail address: wangzj@mail.rcees.ac.cn (Z. Wang).
}

related to a few contaminants. Furthermore, chemical analyses provide little information on the actual or potential biological activities of the contaminants due to effects such as aging, and it cannot be concluded the venomous effects by chemical analyses since the toxicants in actual environment accounting for ecological and healthy risk are chronic and low-dose exposure for a long term. To characterization of the risk in a regional scale, an alternative to chemical analysis is soil screening method, which is a process of identifying and defining areas, contaminants, and condition at the sites that warrant further attention for developing ecological risk assessments. The biologically based bioassays can be used to indicate the presence and potential effects of contaminants as indispensable tools, and therefore, have potential for ecological risk 
assessment (Citterio et al., 2002). A battery of in vitro cell bioassays might be used to rapidly and sensitively screen ecological risk stressors of concern and validate the risk assessment on integrated contamination systems. An efficient (fast and cost effective) screening system through bioassay approach to identify the samples of interest and to provide basic information for further analysis and risk evaluation was developed (Giesy et al., 2002). There is increasing interest for incorporation of toxicity tests (with a battery of different assays) for ecological assessment at hazardous waste sites and for supporting management decisions (Renoux et al., 1995; Salanitro et al., 1997). A series of in vitro bioassays encompassing different toxic mechanisms was applied to determine the estrogenic and dioxin-like compounds in river water in Korea (Oh et al., 2005). Nevertheless, research work on soil with a battery of in vitro cell bioassays on screening levels has been seldom reported to our knowledge.

Among in vitro cell bioassays, the human estrogen receptor recombinant yeast bioassay is a method to determinate estrogenic effects in environment. In general, the recombinant gene yeast test systems rely on yeast constructs expressing an (human) estrogen receptor which upon binding of suited substrates acts as a transcriptional enhancer for an estrogen responsive DNA element-controlled reporter gene, in most cases bacterial $\beta$-galactosidase and thus may serve as a measure for the estrogenic potency caused by chemicals like alkylphenols, bisphenol, biphenylols, and some hydroxy-substituted polycyclic aromatic hydrocarbons (Zacharewski, 1997). EROD with H4IIE rat hepatoma cells bioassay is a bioassay established to measure CYP1A induction caused mostly by dioxin-like chemicals in environmental samples. It is generally regarded as being an early warning signal for the Ah-agonists effects of PCBs, PAHs, and related chemicals (Safe, 1987, 1990). The SOS/umu test has been used for screening mutagens and carcinogens of complex environmental mixtures (Quillardet et al., 1982; Whong et al., 1986). The SOS/umu test system is based on the ability of genotoxins to induce expression of the Umu-C gene, one of the SOS genes responsible for "error-prone repair" and involved in mutagenesis more than other known SOS genes in bacteria (Oda et al., 1985; Ohnishi et al., 1987; Koh and Khim, 2005).

To assess soil quality and characterization of risk, in vitro cell bioassays like recombinant yeast bioassay, EROD bioassay as well as SOS/umu bioassay employed in the study can be used as an initial screening tool or as a "crude yardstick" to gauge the potential toxicity (e.g. Ah-agonists effects, genotoxic effects and estrogenic effects) of contaminants and to quickly identify those areas which clearly do no pose threats to human health or the environment in soil screening levels. The process of soil screening levels is likely to be most useful where it is difficult to determine whether areas of soil are contaminated to an extent that warrants further investigation or response. The screening process can help focus the risk assessment for a site on specific areas, contaminants, and pathways, and data collected in the risk assessment. By screening out areas of sites, potential chemicals of concern or exposure pathways from further investigation, people can limit the scope of the remedial investigation or risk assessment. Soil screening levels can save resources by helping to determine which areas do not require additional attention early in the process. Furthermore, data gathered during the soil screening process can be used in later phases, such as the baseline risk assessment, feasibility study, treatability study, and remedial design. Areas that have been identified for further study become the subject of the remedial investigation and feasibility study. The data collected for soil screening evaluations will be useful in developing the baseline risk assessment.

The aim of this study is to investigate the levels and distribution patterns of estrogenic effects, Ah-agonists effects as well as genotoxic effects in surface soil in Tianjin area, meanwhile to screen for identifying potential ecological risk stressors using a battery of in vitro cell bioassays. Comparison was done among the three different biological effects on a regional scale.

\section{Materials and methods}

\subsection{Sample collection and preparation}

Soil samples were collected from the Tianjin area in May of 2001 (Fig. 1). The air-dried samples were stored in darkness at $4{ }^{\circ} \mathrm{C}$. The sampling locations were set with relatively uniform distribution using a grid design based on approximately equal longitude and latitude; actually they were adjusted by local traffic availability. The sampling locations were concentrated in Yongdingxinhe River, Caobaixinhe River and Qinlongwanhe River drainage areas. The emission of contaminants in the area was either through point sources such as domestic and industrial sewage or through non-point sources like wastewater irrigation, atmospheric deposition, and pesticide application.

At each sampling site, five samples (200 g each) were collected from a $100 \times 100 \mathrm{~m}^{2}$ plot at the depth of $10 \mathrm{~cm}$ (located on the crossing diagonals: four in the corners and one in the crossing point), and then thoroughly mixed to form a composite sample $(1000 \mathrm{~g})$. All of the surface soils were collected using acid-cleaned stainless steel scoops, and then transferred to pre-cleaned amber glass containers. The $\mathrm{pH}$ values of the 41 samples ranged from 5.2 to 9.0. The total organic matters ranged from 0.9 to $3.3 \mathrm{mg} \mathrm{C}^{-1}$. All soil samples were air-dried, sieved ( $1 \mathrm{~mm}$ mesh) and homogenized. After sieving, a $25 \mathrm{~g}$ of air-dried soil sample was immersed in Soxlet for $24 \mathrm{~h}$ and extracted for $48 \mathrm{~h}$ with $200 \mathrm{ml}(1: 1 \mathrm{v} / \mathrm{v})$ dichloromethane/acetone with copper sheet removing sulfur. The solvents were removed by a rotary evaporator (Büchi R-200, Switzerland) and the volume was reduced to $1 \mathrm{ml}$ under a gentle stream of nitrogen blow (Ultra purity, Tangan, China). The solvents were blown to $10 \mu \mathrm{l}$ then redissolved with $200 \mu \mathrm{l}$ of a dimethyl sulfoxide 


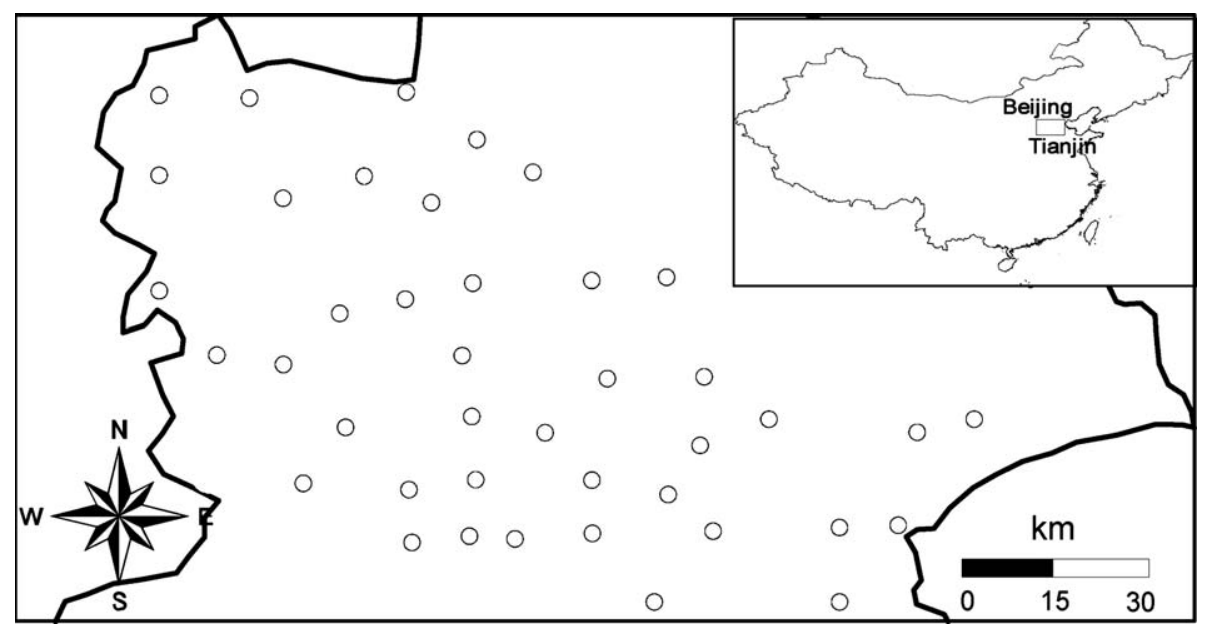

Fig. 1. Sampling locations in Tianjin area.

(DMSO, AMRESCO, USA) and stored in the dark at $4{ }^{\circ} \mathrm{C}$ as bulk solution. Six concentration levels were used for bioassays, and the concentration sequences were obtained by two-fold dilution from bulk solution, however, the final concentration of exchange solvent, DMSO in a bioassay was selected as it is not toxic to any cell bioassays.

\subsection{Study area}

The research area, Tianjin city and its suburb, lies in northern China. It is the third largest industrial center in China (Fig. 1). The total area is approximately $12000 \mathrm{~km}^{2}$ and agriculture is the major land-use in the surrounding suburban and rural areas. From the 1960s to the 1980s, large amounts of pesticides were applied in the agricultural areas of Tianjin. In addition, wastewater has commonly been used to irrigate the soil because of the shortage of water (Tianjin EPB, 1996). Previous work has reported air, water, and soil contaminations in the area by contaminants such as PAHs and polychlorinated biphenyls (PCBs) and organ chlorinated pesticides (TEPB, 1996, 2001). The mean value of the total concentration of 16 PAHs (PAH16) in 41 topsoil samples were and $1.3 \mu \mathrm{g} \mathrm{g}^{-1}$, ranging from 0.2 to $5.2 \mu \mathrm{g} \mathrm{g}^{-1}$ (Tao and Gong, 2004). It was indicated that $p, p^{\prime}$-DDT and $p, p^{\prime}$-DDE were the predominant contaminant in the surface soil samples, with mean concentrations of 27.5 and $18.8 \mathrm{ng} \mathrm{g}^{-1}$, respectively (Tao and Gong, 2004).

\subsection{Human estrogen receptor recombinant yeast bioassay}

The recombinant yeast strain (Saccharomyces cerevisiae) was provided by Dr. J. Sumpter in Brunel University, UK. Yeast culture and galactosidase measurement was carried out according to the assay procedure of Routledge and Sumpter (1996) followed with the slightly modified procedures (Wu et al., 2002). Briefly, 50-100 $\mu 1$ of a concentrated recombinant yeast stock was added to $10 \mathrm{ml}$ synthetic complete (SC) medium with $10 \mu \mathrm{CuSO}_{4}$ and incubated $20 \mathrm{~h}$ at
$30{ }^{\circ} \mathrm{C}$ in a shaking incubator $\left(130 \mathrm{r} \mathrm{min}^{-1}\right)$, then the assay medium was diluted by SC medium until an optical density (OD) of 0.25 at a wavelength of $600 \mathrm{~nm}$ with a spectrophotometer (Tecan-GENios, Australia) was reached. Six-fold 1:1 dilution series were prepared. The dilution series, solvent blank and the $17 \beta$-estradiol as positive control were tested in triplicate. Clear plastic 96-well plates were seeded with $200 \mu 1$ per well of the assay medium containing yeast and dilution series, using a 12-well multi-channel pipettor. The presence of estrogenic chemicals in sample is confirmed via a color change from transparent to yellow. A calibration using $17 \beta$-estradiol standard gradient was run $\left(0.01-20 \mathrm{nmol} \mathrm{ml}^{-1}\right.$ in DMSO and $N=11$ ) and the strengths of estrogen in soil organic extracts were reported in terms of $\mathrm{ng} \mathrm{kg}^{-1}$ d.w. $17 \beta$-estradiol equivalent concentrations (EEQs). The minimum detectable concentration was 40.0 pg TEQ well ${ }^{-1}$.

\subsection{EROD with H4IIE rat hepatoma cells bioassay}

The bioassay procedure has been validated in our laboratory for measuring the dioxin-like activity in environmental samples (Ma et al., 2005). Rate hepatoma cell lines (H4IIE) was obtained from the American Type Culture Collection, and cultured with cell culture medium containing Dulbecco's MEM (DMEM, containing $1.0 \mathrm{~g} \mathrm{l}^{-1}$ D-Glucose, $3.7 \mathrm{~g}^{-1} N$-acetyl-L-alanyl-L-glutamine, Berlin, Germany), $10 \%$ fetal bovine serum, 100 units $\mathrm{ml}^{-1}$ penicillin, and $100 \mu \mathrm{g} \mathrm{ml}^{-1}$ streptomycin. The cell culture and EROD bioassay were performed following Donato's method (Donato et al., 1992). For each concentration level, three duplicates and solvent blank were used on one 96-well plate. Along with each plate in the same time of measuring environmental samples, a calibration using 2,3,7,8-tetrachlorodibenzo-p-dioxin (TCDD) standard gradient was run (0-28 $\mathrm{ng} \mathrm{ml}^{-1}$ in DMSO and $N=9$ ). The TCDD equivalent concentrations (TEQs) in soil samples were then calculated according to the calibration curve. The minimum detectable concentration is $0.02 \mathrm{pg}$ TEQ well ${ }^{-1}$. If necessary, the extract of soil sample was diluted to fit the linear 
part of the TCDD dose-response curve, and the best-fitting part run at the same time was chosen to calculate the TEQs of the bulk sample. The data from EROD measurement were inputted to a curve-fitting program:

$y=\frac{(A-D)}{\left(1+\left(\frac{x}{C}\right)^{B}\right)}+D$

where $A$ is $y$ value of lower asymptote, $B$ is relative slope of middle region, $C$ is $x$ value at midpoint of curve, $D$ is $y$ value of upper asymptote and is fitted to a sigmoid curve.

\subsection{SOS/umu test}

The SOS/umu test was carried out according to the method of Oda et al. $(1985,1995)$. The tester strain Salmonella typhimurium TA1535/PSK1002 was provided by Osaka Prefectural Institute of Public Health, Japan. In the experiment, the tester strain was grown in TGA medium overnight at $37^{\circ} \mathrm{C}$. After the incubation period, the optical density $(600 \mathrm{~nm})$ was adjusted to 0.3 by addition of fresh TGA medium. The 96-well microplate was incubated for $2 \mathrm{~h}$ at $37^{\circ} \mathrm{C}$, and then the optical density $(600 \mathrm{~nm})$ of each microplate well was measured to quantify growth inhibition during the exposition (toxicity assay). The optical density $(420 \mathrm{~nm}$ and $550 \mathrm{~nm}$ ) was measured after the incubation to determine $\beta$-galactosidase activity. DMSO was taken as a solvent control, and the samples and solvent blank were tested in triplicate. Data from the measurement was calculated by

$A=\frac{1000(B-1.75 \times C)}{t \times v \times D}$

where $A$ is the activity of $\beta$-Galactosidise, $B$ is optical density at $420 \mathrm{~nm}, B$ is optical density at $550 \mathrm{~nm}, C$ is optical density at $600 \mathrm{~nm}, t$ is the incubation duration ( $\mathrm{min}$ ) of the enzyme reaction, $v$ is the dilution rate of bacterial suspension $(\mathrm{ml})$.
To avoid interferences, the genotoxicology assessment was quantitatively expressed as induction ratios $(I R=$ $\left.A_{\text {sample }} / A_{\text {solventblank }}\right)$ under a given amount of soil for extraction. The result is considered to be positive if the $I R$ is higher than 2.0 , which means the genotoxic potency of sample to induce a two-fold increase to that of solvent blank. The $I R$ below 2.0 is scored as non-genotoxic (negative) result.

Meanwhile, the genotoxic potency for samples scored as positive result can also be expressed as soil weight $(S W)$ required for the extract to lead positive result (IR 2.0) and could be obtained from the dose-response relationship.

$S W=\frac{V V_{1} W}{5 n V_{2} V_{t}}$

where $W$ is the soil weight for Soxlet $(\mathrm{g}), n$ is the dilution rate at $I R=2.0, V_{t}$ is the bulk solution volume redissolved in $200 \mu \mathrm{DMSO}, V$ is the volume of bulk solution for the concentration sequences ( $50 \mu \mathrm{l}), V_{1}$ is the volume of culture in SOS/umu test $(\mu 1), V_{2}$ is the volume of the bulk solution on different concentration sequences.

In comparison, $S W$ can be more scientifically justified endpoint. In general, the $I R$ value depends on the soil amount used for extraction, and a positive result could be obtained by simply increasing the amount of soil. Different $I R$ cannot reflect the relative genotoxic potency of soil samples in the regional scale because the curve slope of dose-response relationship depends on the characteristics of soil contaminants. In contrary, $S W$ was obtained from the dose-response curve in a similar manner as other toxicological endpoints, such as $\mathrm{LC}_{50}$.

\subsection{Spatial analysis and mapping}

Spatial distribution of estrogenic effects Ah-agonists effects and genotoxic effects in Tianjin area were generated from the results of 41 discrete sampling locations using kriging interpolation with medium smoothing (Figs. 2-4, for

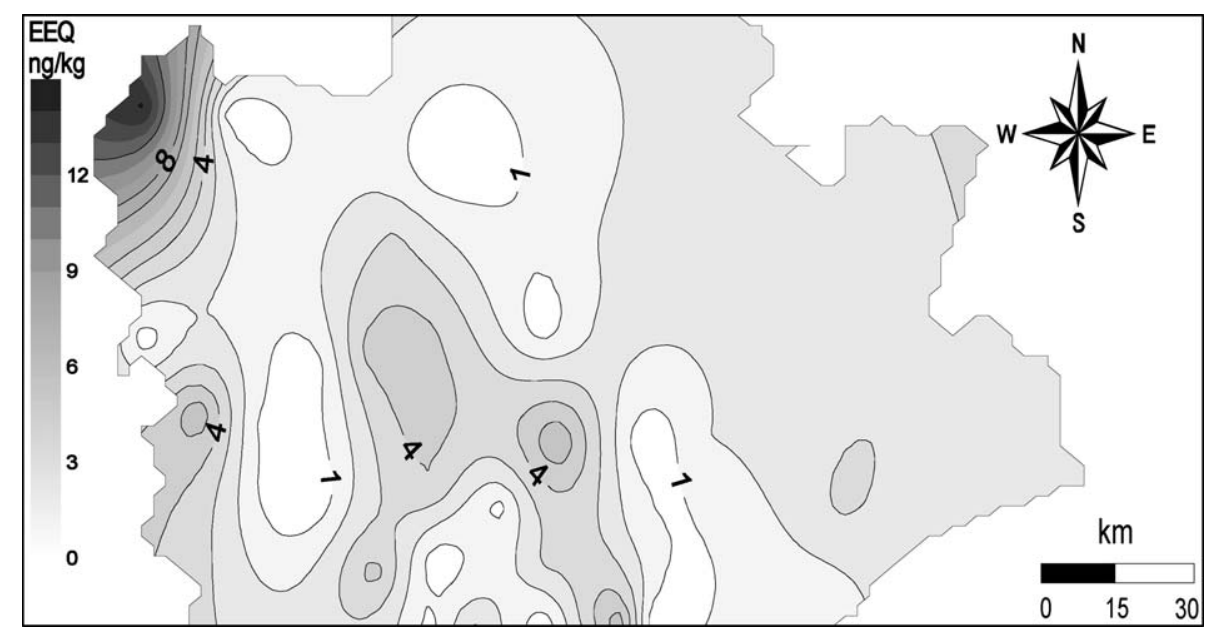

Fig. 2. Spatial distribution of estrogenic effects in surface soil in Tianjin area. 


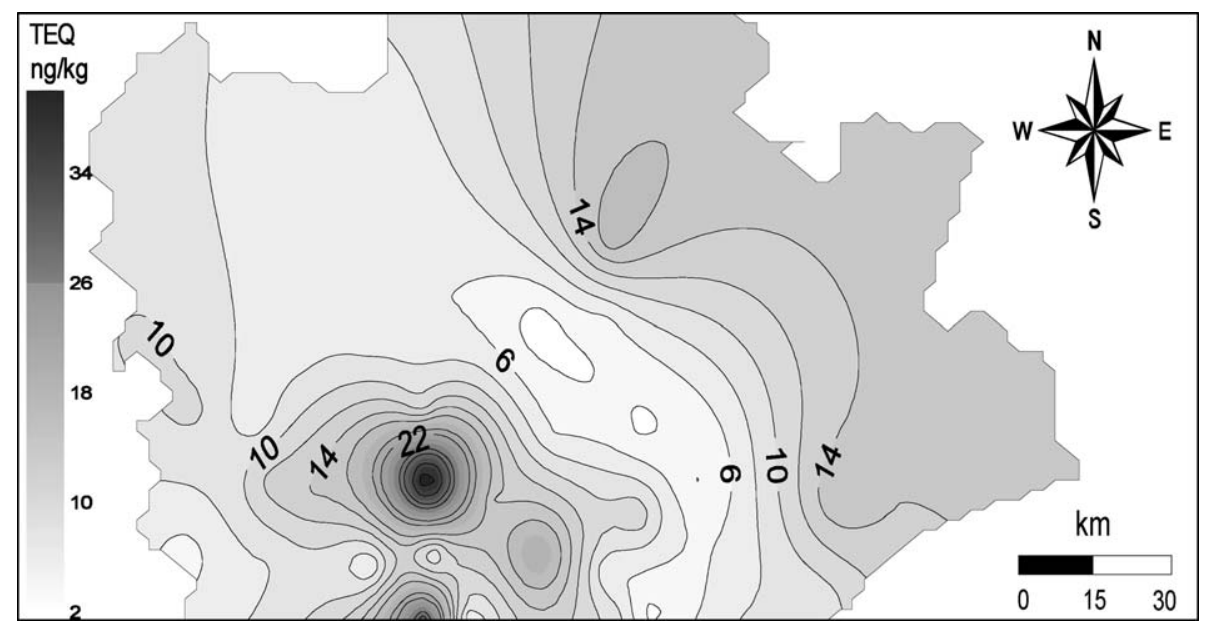

Fig. 3. Spatial distribution of Ah-agonists effects in surface soil in Tianjin area.

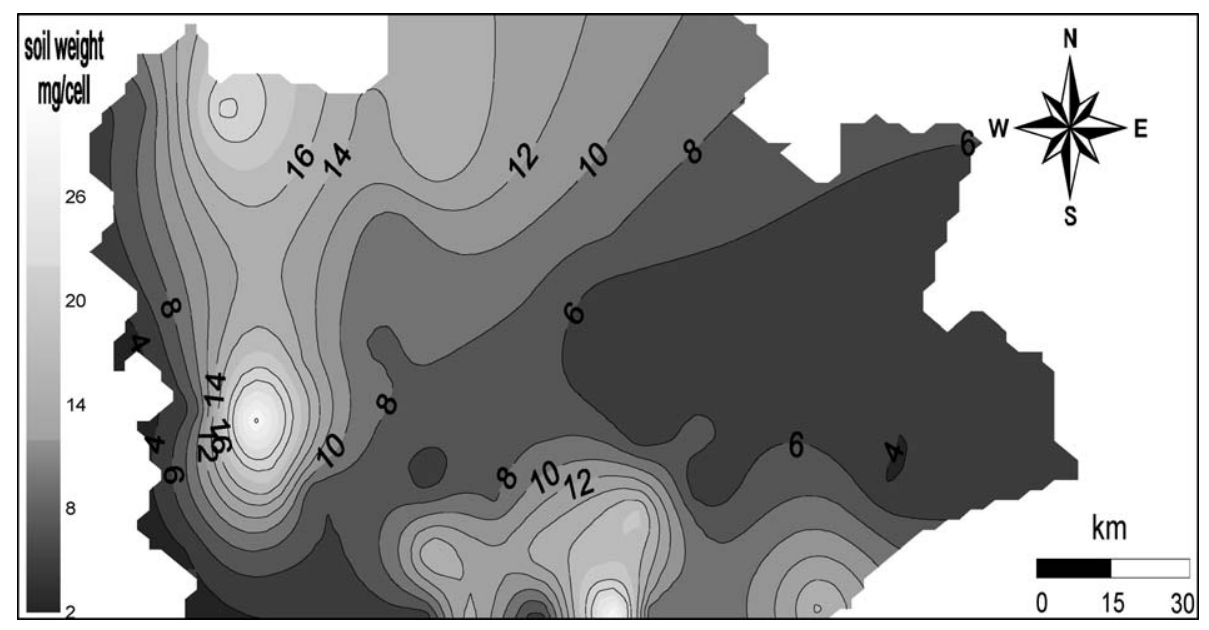

Fig. 4. Spatial distribution of genotoxic effects in surface soil in Tianjin area.

estrogenic effects, Ah-agonists effects and genotoxic effects respectively) by Golden Software Surfer v.7.0 (Golden Software, Inc.).

\section{Results and discussion}

The statistical descriptions of results from the three bioassays were listed in Table 1. Estrogenic effects of the soil samples collected from 41 sites in the Tianjin area, North- ern China were quantified in terms of biological $17 \beta$-estradiol equivalent concentrations (EEQs). Total estrogenic activity in these soil samples was measured to be between 0.1 and $14.2 \mathrm{ng} \mathrm{EEQ} \mathrm{kg}^{-1}$ soil (d.w.) with a mean value of $2.5 \mathrm{ng}$ EEQ $\mathrm{kg}^{-1}$ soil (d.w.). The highest level of estrogenicity in soil organic extracts was distributed in the northwest of Tianjin area, which is called Wuqing District. It was reported that the estrogenic activity of sediment in Lake Shihwa, Korea expressed as EEQs ranged from

Table 1

Statistical descriptions of the results of three in vitro cell bioassays

\begin{tabular}{lccc}
\hline & In vitro cell bioassays & & \\
\cline { 2 - 4 } & Estrogenic effects (ng EEQ kg & \\
\hline Mean & d.w.) & Ah-agonists effects (ng TEQ kg ${ }^{-1}$ d.w.) & Genotoxic effects (mg soil well $^{-1}$ ) \\
Maximum & 2.50 & 10.42 & 10.51 \\
Minimum & 14.20 & 42.56 & 31.25 \\
Standard deviation & 0.06 & 2.84 & 3.91 \\
Coefficient variation & 2.63 & 7.64 & 6.95 \\
\hline
\end{tabular}


$3.3 \mathrm{ng}$ EEQ $\mathrm{kg}^{-1}$ to $64 \mathrm{ng}$ EEQ $\mathrm{kg}^{-1}$ (d.w.), with an average of $21 \mathrm{ng}$ EEQ kg${ }^{-1}$ (d.w.) (Koh and Khim, 2005). It was also reported that 12 marine sediments sampled from industrialized areas in the Dutch Wadden Sea showed the estrogenic potency ranging from $5 \mathrm{nmol}$ EEQ $\mathrm{kg}^{-1}$ to 40 nmol EEQ $\mathrm{kg}^{-1}$ (Legler et al., 2002). Therefore, the estrogenicity assayed in present soils was much lower than those in above mentioned sediments.

Total content of Ah-receptor agonists in an environmental sample can be quantitatively with respect to its biological 2,3,7,8-tetrachlorodibenzo- $p$-dioxin equivalent concentrations (TEQs). The measured values ranged from $2.8 \mathrm{ng}$ TEQ $\mathrm{kg}^{-1}$ soil (d.w.) to $42.6 \mathrm{ng}$ TEQ $\mathrm{kg}^{-1}$ soil (d.w.). The mean for all samples was $10.4 \mathrm{ng}$ TEQ $\mathrm{kg}^{-1}$ soil (d.w.), with a standard deviation of $7.6 \mathrm{ng}$ TEQ $\mathrm{kg}^{-1}$ soil (d.w.) and coefficient of variation $73.3 \%$. Since EROD activity was considered as a biomarker of exposure to PAHs, PCBs, and dioxin-like compounds, the results suggested the presence of these types of contaminants in the Tianjin area. There were limited data of concerns in the literature. The TEQs levels in top soil in rural settings north of Stockholm, Sweden were from $0.5 \mathrm{ng}$ TEQ $\mathrm{kg}^{-1}$ to $2.0 \mathrm{ng}$ TEQ $\mathrm{kg}^{-1}$ soil (d.w.) (Broman et al., 1990), and those in soil samples collected from Ya Er Lake area, Hubei, China ranged from $1.8 \mathrm{ng}$ TEQ $\mathrm{kg}^{-1}$ soil (d.w.) to $2.3 \mathrm{ng}$ TEQ $\mathrm{kg}^{-1}$ soil (d.w.) (Xu et al., 1996). Therefore, it has been indicated that the levels of Ah-agonists in Tianjin area were higher than those from the compared areas.

At given amount of soil for extraction, the results of genotoxicity scored as positive results $(I R>2.0)$ accounted for $53.7 \%$ of all soil samples, and the negative results accounted for $46.3 \%$. The induction ratios $(I R)$ for 41 soil samples collected from Tianjin area ranged from 1.0 to 4.6, with the average of 2.4. In the literature, there is little work on screening the genotoxicity of soil. The genotoxicity expressed as $I R$ values were higher than the soil taken from an engineered biopile at the Czechowice-Dziedice Polish oil refinery with a mean value of 0.86 (Plaza and Jawecki, 2005), which was obviously lower than those observed in the present work. For those soil samples scored as positive, values of $S W$ were between $3.91 \mathrm{mg}$ soil and $31.3 \mathrm{mg}$ soil (d.w.) per well with a mean value of $10.5 \mathrm{mg}$ soil (d.w.) per well.

These figures revealed marked differences in distribution of toxicities from region to region in Tianjin area. In Fig. 2, the higher estrogenic potencies area was close to the northwest part of Tianjin area, which is a place borders on Beijing and Tianjin, and has received the loads of domestic and industrial sewage from upstream area and local sewage discharge for irrigation for more than 40 years (Jin et al., 2004). It was also reported that the estrogenic chemicals, such as 4-tert-octylphenol, 4-nonylphenol and bisphenol A were determined in surface water samples from Haihe River which is a mainstream of the study area, in a range of 18.0-20.2 $\mathrm{ng} \mathrm{1}^{-1}, 106-296 \mathrm{ng}^{-1}$ and 19.1-106 $\mathrm{ng} \mathrm{l}^{-1}$, respectively (Jin et al., 2004). The higher estrogenic effects in this area might be caused by effluent from upstream area.
The relatively high values of Ah-agonists effects demonstrated in Fig. 3 were around the urban area of Tianjin. The measured EROD induction could probably be attributed to the contaminants in soil. In the area with high values of Ah-agonists effects, the principal sources of soil contamination likely to induce EROD activities were pesticides and other chemicals applied to the agricultural surrounding fields. Other potential sources of ERODinducing contaminants were consumption of large quantities of fossil fuel (coal, oil, and natural gas), which released PAHs into the air. Indeed, dry and wet atmospheric fallout may also lead to the transfer of polycyclic hydrocarbon contaminants to the soil, either directly or indirectly via soil leaching or run-off in the river.

In Fig. 4, the mapping indicated that the higher levels of genotoxic effects in soil organic extracts were distributed in the urban of Tianjin, as well as in nearby the coastal towns Tanggu and Hangu Districts on northeast part of Tianjin. As indicated by comparing two figures (Figs. 3 and 4), the urban area of Tianjin underwent high levels of Ah-agonists effects and genotoxic effects simultaneously.

The distribution pattern of Ah-agonists effects was similar to that of genotoxic effects in surface soil in Tianjin area. To evaluate the relationship of the two effects, both $I R$ and TEQs were logarithmically transformed for normality (one-simple Kolmogorov-Smirnov test) $(p>0.05)$, and $\log I R$ was used to analyze any relationship with the $\log$ TEQs by non-parametric correlations (Spearman's rho). Although no correlation was found between them, there were nine points where they influenced significantly the correlation between the two variables. Weeding out the exceptional points, It could be seen that there was a positive significant correlation coefficient $(r)=0.047(p=$ $0.008, n=32$ ) as shown in Fig. 5, indicating a fair agreement of the spatial distribution patterns between Ah-agonists effects and genotoxic effects. Among these exceptional points, some were from mountain areas where

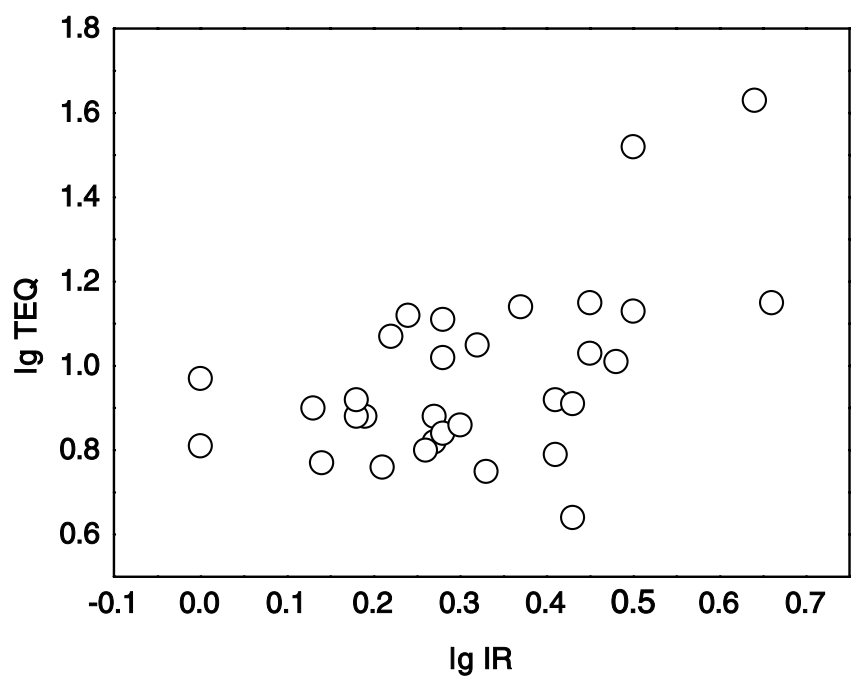

Fig. 5. Relationship between $\log I R$ and $\log$ TEQs. 
greater amount of pesticides was used during the 1970s to protect the forests (Tianjin EPB, 1996) while others were from the wastewater irrigation area. The main factor reported by Pacheco and Santos (2001) for the spatial similarity was that surface soil contained various progenotoxic PAHs, which highly induced EROD activity, which simultaneously may be environmentally biotransformed into reactive genotoxic compounds leading to genotoxic effects in terrestrial species. Nevertheless, no correlation between estrogenic effects and Ah-agonists effects was exhibited. Spink et al. (1992) and reported that one of causes for the difference was that EROD activity is known to be induced by exposure to PAHs and dioxin-like compounds, and induction of antiestrogenic activity by most of these chemicals is reportedly mediated by the Ah-receptor. One mechanism (Arcaro et al., 1999) which has been proposed for Ah-receptor-mediated antiestrogenicity is enhanced E2 metabolism as the result of the Ah-receptor-mediated induction of CYP1A activity.

\section{Conclusions}

In summary, the investigation on surface soil quality in Tianjin area, China using a battery of in vitro cell bioassays has demonstrated the presences of considerable contaminants which would cause estrogenic, Ah-agonists, and genotoxic effects. The estrogenic potency was observed to be higher in northwest part of Tianjin than in other regions. High levels of Ah-agonists effects were distributed in the urban area and high levels of genotoxic effects were also in the urban area. The distribution pattern of Ah-agonists effects in surface soil was markedly different from that of estrogenic effects, while the distribution patterns of Ah-agonists effects and genotoxic effects in surface soil exhibited significant positive correlations with each other. We concluded that a battery of in vitro cell bioassays encompassing different toxic mechanisms could provide useful information regarding ecological risk assessment and identifying ecological risk stressors on a regional scale. However, chronic and mixed exposure to low levels of chemicals, and the toxicity identification evaluation are needed for further study.

\section{Acknowledgements}

This work was supported by National Basic Research Program of China (2003CB415005) and National Scientific Foundation of China (40471129). Thanks are also due to Prof. S. Tao in Peking University, China for help in soil sampling.

\section{References}

Arcaro, K.F., O'Keefe, P.W., Yang, Y., 1999. Antiestrogenicity of environmental polycyclic aromatic hydrocarbons in human breast cancer cells. Toxicology 133, 115-127.

Broman, D., Rolff, C., Zebuhr, Y., 1990. Analysis of polyehlorinated dibenzo- $p$-dioxins (PCDD) and polychlorinated dibenzofurans
(PCDF) in soil and digested sewage sludge from Stockholm, Sweden. Chemosphere 21, 1213-1220.

Citterio, S., Aina, R., Labra, M., 2002. Soil genotoxicity assessment: a new strategy based on biomolecular tools and plant bioindicators. Environ. Sci. Technol. 36, 2748-2753.

Donato, M.T., Castell, J.V., Gomez-Lechon, J., 1992. A rapid and sensitive method for measure minooxygenase activities in hepatocytes cultured in 96-well plates. J. Tiss. Cult. Meth. 14, 153-158.

Fernandez, M.D., Cagigal, E., Vega, M.M., 2005. Ecological risk assessment of contaminated through direct toxicity assessment. Ecotox. Enviorn. Safe. 62, 174-184.

Giesy, J.P., Hilscherova, K., Jones, P.D., Kannan, K., 2002. Cell bioassays for detection of aryl hydrocarbon (AhR) and estrogen receptor (ER) mediated activity in environmental samples. Mar. Pollut. Bull. 45, 3-16.

Jin, X.L., Jiang, G.B., et al., 2004. Determination of 4-tert-octylphenol, 4nonylphenol and bisphenol-A in surface waters from Haihe River in Tianjin by gas chromatography-mass spectrometry with selected ion monitoring. Chemosphere 56, 1113-1119.

Koh, C.H., Khim, J.S., 2005. Instrumental and bioanalytical measures of dioxin-like and estrogenic compounds and activities associated with sediment from the Korean coast. Ecotox. Environ. Safe. 61, 366-379.

Legler, J., Dennekamp, M., et al., 2002. Detection of estrogenic activity in sediment-associated compounds using in vitro reporter gene assays. Sci. Total Environ. 293, 69-83.

Ma, M., Wang, C.X., Wang, Z.J., 2005. Assessing toxicities of hydrophobic organic pollutants in Huaihe river by using two types of sampling. Environ. Sci. Heal. A. 40, 331-342.

Moore, M.N., Depledgeb, M.N., Readmana, J.W., 2004. An integrated biomarker-based strategy for ecotoxicological evaluation of risk in environmental management. Mutat. Res. 522, 247-268.

Oda, Y. et al., 1985. Evaluation of the new system (umu-test) for the detection of environmental mutagens and carcinogens. Mutat. Res. 147, 219-223.

Oda, Y., Yamazaki, H., Watanabe, M., et al., 1995. Development of high sensitive umu test system: rapid detection of genotoxicity of progenotoxicaromatic amines by Salmonella typhimurium NM2009 possessing high $O$-acetyltransferase activity. Mutat. Res. 334, 145-156.

Oh, S.M., Park, K., Chung, K.H., 2005. Combination of in vitro bioassays encompassing different mechanisms to determine the endocrinedisrupting effects of river water. Sci. Total Environ.

Ohnishi, T., Iwanmoto, S., Ikai-tano, K., Nozu, K., 1987. Induction of umu gene expression by cross-links and other DNA lesson. Mutat. Res. $184,7-11$.

Pacheco, M., Santos, M.A., 2001. Biotransformation, endocrine, and genetic responses of Anguilla anguilla L. to petroleum distillate products and environmentally contaminated waters. Ecotox. Environ. Safe. 49, 64-75.

Plaza, G., Jawecki, G.N., 2005. Assessment of genotoxic activity of petroleum hydrocarbon-bioremediated soil. Ecotox. Environ. Safe. 62, 415-420.

Quillardet, P., Huisman, O., D' Ari, R., Honug, M., 1982. SOS chromotest a test assay of induction of an SOS function in Escherichia coli K12 to measure genotoxicity. Proc. Natl. Acad. Sci. (USA) 79, 5971-5975.

Renoux, A.Y., Tyagi, R.D., Roy, Y., Samson, R., 1995. Ecotoxicological assessment of bioremediation of a petroleum soil. In: Hinchee, R.E., Brockman, F.J., Vogel, C.M. (Eds.), Microbial Processes for Bioremediation. Battelle, Columbus, OH, USA, pp. 259-264.

Routledge, E.J., Sumpter, J.P., 1996. Estrogenic activity of surfactants and some of their degradation products assessed using a recombinant yeast screen. Environ. Toxicol. Chem. 15, 241-248.

Safe, S., 1987. Determination of 2,3,7,8-TCDD toxic equivalent factors (TEFs): support for the use of in vitro AHH induction assay. Chemosphere 16, 791-802.

Safe, S., 1990. Polychlorinated biphenyls (PCBs), and dibenzo-p-dioxins (PCDDs), dibenzofurans (PCDFs) and related compounds: environmental and mechanistic considerations which support the develop- 
ment of toxic equivalency factors (TEFs). Crit. Rev. Toxicol. 21, $51-88$.

Salanitro, J.P., Dorn, P.B., Huesemann, M.H., Moore, K.O., Rhodes, I.A., Jackson, L.M., Vipond, T.E., Western, M.M., Wisniewski, H.L., 1997. Crude oil hydrocarbon bioremediation and soil ecotoxicity assessment. Environ. Sci. Technol. 31, 1769-1776.

Snape, J.R., Maund, S.J., Pickford, D.B., 2004. Ecotoxicogenomics: the challenge of the integrating genomics into aquatic and terrestrial ecotoxicology. Aquat. Toxicol. 67, 143-154.

Spink, D.C., Eugster, H.P., Lincoln, D.W., 1992. 17ß-Estradiol hydroxylation catalyzed by human cytochrome P4501A1 a comparsion of the activities induced by 2,3,7,8-tetrachlorodibenzo- $p$-dioxin in MCF-7 cells with those from heterologous expression of the cDNA. Arch. Biochem. Biophys. 293, 248-342.

Tao, S., Gong, Z.M., 2004. Level and distribution of DDT in surface soils from Tianjin, China. Chemosphere 54, 1247-1253.
TEPB (Tianjin Environmental Protection Bureau), 1996. Environmental Quality Statement (1986-1990). Tianjin Environmental Protection Bureau, Tianjin (in Chinese).

TEPB (Tianjin Environmental Protection Bureau), 2001. Environmental Quality Statement (1996-2000). Tianjin Environmental Protection Bureau, Tianjin (in Chinese).

Whong, W.Z., Wen, Y.F., Stewart, J., Ong, I., 1986. Validation of the SOS/ umu-test with genotoxic complex mixtures. Mutat. Res. 175, 139-144.

Wu, W.Z., Wang, J.X., Xu, Y., 2002. Recombinant gene yeast for assaying environmental estrogen pollutants. China Environ. Sci. 22, $60-63$.

Xu, Y., Wu, W.Z., Zhang, Y.Y., 1996. Rapid quantitative screening of dioxin-like compounds by EROD induction bioassay. China Environ. Sci. 16, 279-284.

Zacharewski, T., 1997. In Vitro bioassays for assessing estrogenic substances. Crit. Rev. Environ. Sci. Technol. 31, 613-624. 